\title{
Research on history of Chinese seismology*
}

\author{
Rui Feng ${ }^{1, \star}$ and Yuxia $\mathrm{Wu}^{2}$ \\ ${ }^{1}$ Institute of Geophysics, China Earthquake Administration, Beijing 100081, China \\ ${ }^{2}$ China Earthquake Networks Center, Beijing 100045, China
}

\begin{abstract}
The history of Chinese seismology can be traced back to four thousand years before and divided into four stages, i.e., primitive knowledge, worship of nature, perceptual knowledge and scientific research. The second stage ran in the whole Qin-Han dynasties, and the fourth stage began from Emperor Kangxi in Qing Dynasty and continued to the present. So far China has made four great contributions to seismological development of the world, i.e., the invention of Heng Zhang's seismoscope, great amount of historical records of earthquakes of four thousand years, most abundant anomaly data before earthquakes, and successful practice of earthquake prediction in Haicheng. However, the seismological research in China at present is still on the junior and developing stage. Now we have been carrying on some recessively historical load in our mind such as the subconsciousness of absolute obedience, habit of phenomenological study as well as the methods of philosophical analysis without sincerity. For constructing a high-level Chinese culture in seismological research, we need to pay attention to combining the phenomenological research with experiment, observation and theory study. It is also suggested to take the appropriated measures matched with the present research level in seismology, as well as to promote coexisting and merging of multi-cultures.
\end{abstract}

Key words: culture tradition; phenomenological research; earthquake prediction; culture in science CLC number: P316 Document code: A

\section{Introduction}

So far, Chinese seismologists have not only reaped the joy and glory for successful forecast of Haicheng earthquake in 1975, suffered bitterness and censure for failure to predict Tangshan earthquake in 1976, but had their rebirth through blood baptism in Wenchuan earthquake in 2008. Unfortunately, this is the present capacity of earthquake prediction, which will continue for a rather long period of time to come. The deaths of 242000 in Tangshan and over 90000 in Wenchuan make it evitable for us to make self-analysis and self-criticism while summing up technological lessons.

One of the approaches to self-analysis is to have a study on the history of science, taking history as a mirror to get a clear idea of "where I come from and where I am going to", to check the shortcomings in our thinking mode and research practice, and to keep us alerted to

\footnotetext{
* Received 12 December 2009; accepted in revised form 21 January 2010; published 10 June 2010.

^ Corresponding author. e-mail: rfeng_cn@yahoo.com.cn

(C) The Seismological Society of China and Springer-Verlag Berlin Heidelberg 2010
}

our hidden weakness attributable to our cultural tradition but still unaware, which calls for self-analysis and overcoming. Only by that are we able to do a better job in future.

It was assumed that China's earliest recorded earthquake was one that happened in Shanxi province (or South China, according to other study) in the 23rd century BC in the period of Shun. And this assumption is based on description from the Peace Book for Imperial Inspection by Fang Li in the Song Dynasty (960 AD-1279 AD): "Mozi said when the three ethnic peoples were dying out, an earthquake caused a spring appearing". But investigations have revealed that there is no such text in the work of Mozi written in the Spring and Warring States Period (1046 BC-256 BC), and it proves to be a time-honored story made up a thousand years later, thus hardly accurate (Li, 1981). As we see now, the comparatively definite and continued documentation of earthquake should have begun with the Xia Dynasty (2070 BC-1600 BC), and these earthquakes happened in Shandong, He'nan, Shaanxi in 1831 BC, $1767 \mathrm{BC}$ and $1189 \mathrm{BC}$, respectively. These events are recorded in the Bamboo Book Annals, which is obtained 
by sorting out dozens of carts of fragmentary inscribed bamboo-slips of the Warring States Period discovered in Ji County, He'nan, in the early days of the Western Jin Dynasty (around 280 AD). Based on this, from 1831 BC, it is approximately 4000 years since Chinese people began to study earthquake. Here is a sequential elaboration on their study in historical stages: the stage of primitive perception, of natural worship, of perpetual knowledge, and of scientific exploration.

\section{First stage: Primitive perception}

Before the Qin Dynasty (221 BC-206 BC) or during the whole period before Emperor $\mathrm{Wu}$ of the Han Dynasty came to the throne (140 BC), the knowledge of earthquake of Chinese people was in a state of primitiveness and naive materialism. The early people only noticed the grand phenomena available to their naked eyes and left behind such simple words as "the earth trembled and ruptured, all the rivers were rocking, lighting bolts kept striking, mountains were collapsing, springs gushing along, and houses damaged". There were no more than 30-odd accounts of earthquakes, mostly of them in the drainage basin of the Yellow River, involving Shanxi, Hebei, Shandong, He'nan, and Shaanxi provinces.

According to the silk manuscript of the Chu State of the Warring States Period, the oldest and best preserved book on astronomy discovered so far in China (Feng, 2001), when the earth and sky began to form, Fuxi and Nüwa gave birth to four sons, then the father and mother was in charge of the sky and earth, while the four sons the four seasons. Fuxi managed the sun with 'Ju' (i.e., rule of square) and Nüwa the moon with 'Gui' (i.e., compasses) (Figure 1); the ' $J u$ ' was used to draw squares and the 'Gui' circles, and hence the regular running of the world under the rule of the 'Gui' and ' $\mathrm{Ju}$ ', and the structure of "round sky and square earth" is that a arch-roofed sky, supported by four towering columns on four sides, was erected on the earth of China. And birth of the world was to be accompanied by earthquakes.

In prehistoric times, the Four Poles collapsed and the land of China ruptured, the sky was no longer to shelter the whole land, nor the land to support the things on it any longer... Then Nüwa extracted the Five-color Rocks to mend the sky and cut the feet of sea turtles to replace the former Four Poles (Huainanzi).

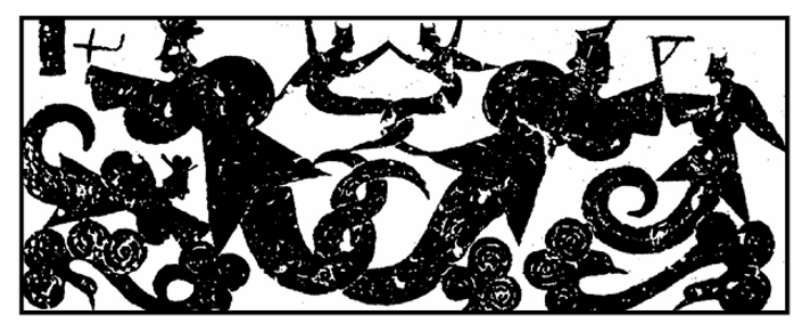

Figure 1 Carved stone figures of Fuxi and Nüwa (in the Eastern Han Dynasty, 25 AD-220 AD, a temple of Shandong province). Fuxi (right) in charge of the sun holds a 'Ju' in his left hand and Nüwa (left) in charge of the moon holds a 'Gui' in her right hand. The man and his wife, both deities, human-headed and snake-boded, created a world of mankind.

In simple words, in prehistoric times, the land all over the world collapsed and ruptured, the four heavenly pillars (the four poles), and consequently, the sky was no longer able to give shelter to the land, nor the land to bear everything on it any longer. Then Nüwa rose to the occasion. She extracted rocks to mend the sky and cut off the four feet of the sea turtle to support the canopy of the sky. This was maybe the first earthquake that happened at the birth of us mankind, and origin of the concept of "the sky collapsing and land sinking". But, in reality, the sky has never collapsed and only earthquake can cause collapse of caves and human deaths. So it is likely that the story of "extracting rocks to mend the sky" is a mythological misrepresentation of the act of "picking rocks to mend mountain caves", which sounds more realistic. Then how did the earthquake happen? There is another story. It is said that the rebellious Gong Gong fought with Zhuan Xu for the throne but failed, then in a rage he knocked into the Buzhou Mountain and brought about an earthquake.

\section{In former times, Gong Gong, competed with Zhuan Xu for the throne, bumped into Buzhou Maintain, and the heavenly pillars collapsed and the cable tying the heavenly canopy was torn apart (Huainanzi).}

Here, the tumbling of the heavenly pillars refers to the collapse of the Four Poles; the break of the cables of the earth means the rupture of the cables that were used to tie the heavenly canopy, thus the earthquake was caused by Gong Gong.

People in the Xia and Shang dynasties (about 2070 BC-1046 BC) worshipped only the sun. Therefore, any occurrence of violation against the sun, saying the solar 
eclipse or eclipse with earthquake, would be regarded as a catastrophe to the world. Gradually, their worshipping objects evolved to be three deities representing the sun, moon and earth respectively, that is $\mathrm{Xi} \mathrm{He}$, Chang $\mathrm{Xi}$ and Zhu Long. Xi He is the mother of ten sons (suns), and Chang $\mathrm{Xi}$ the mother of 12 daughters (moons). Chinese character of ' $\mathrm{Xi}$ ' refers to air or thin floating clouds. So it follows that since time memorial people can see only the sun and the moon but never their beautiful mothers.

The third deity, Zhu Long (latent dragon or fire dragon), a god in the Genesis involved in earthquake is also called the "Kun". It refers to the black dragon of the East Palace that lies under the dormant Northern Pole in the coldest days of the year, but in spring "turns into a bird called Peng", and then we have got a famous idiom "Kun Peng spreads out its wings". The snake-bodied Zhu Long is a thousand miles long. When it opens its eyes, it is daytime; when it closes its eyes, it is night. The dragon head holds a torch (namely a candle, or a fire) to light up the gate to earth and shed light into the nether world, and for that reason it is also called the God of Lighting up the Nether World. He lies deeply beneath the Zhong Mountain, eating and drinking nothing, sleepless, and holing its breath, and then calm and peace reign above the earth; but whenever it begins to breathe its breath will turn into strong winds which rock the earth violently (Figure 2). The dragon, shaped by a heap of clam shells represented in the drawing of the winter solstice among the dragon figures of the 6500 year old Yang-shao Civilization unearthed in He'nan in 1988, is considered by archaeologists as Zhu Long. Limited by their cognitive capacity, people in ancient time believed that earthquake was created by huge serpents that can travel through the earth, and that snakes were dragons which inspired horror and awe. The seismoscope invented by Heng Zhang is featured with "eight dragons on the exterior holding brass balls in the mouths" (The Book of the Later Han), suggesting that Zhu Long is the cause of earthquakes, for the brass balls signify torches held by Zhu Long. The dragon worship of Chinese ancient times was in reality directed to both the heaven and earth.

The Chinese character '震' (zhen) originally referred to the thunderbolt. The time when the clam opens its mouth in spring is called '辰' (the bottom half of the character '震'). When spring winds bring rains, the spring thunder begins to peal, and then the character '雨, (rain) is added onto '辰' to form the character of '震'. The holy dragon carries the enormous and explosive power of thunderbolt. Here is what is written in an ancient work: "Zhen (震) means thunderbolt, i.e., the dragon". In Chinese historical books a thunderbolt in the sky is called "heaven-quake"; thunderbolt on the earth an "earth-quake". But in either case, it was regarded as a show of anger of the holy dragon.

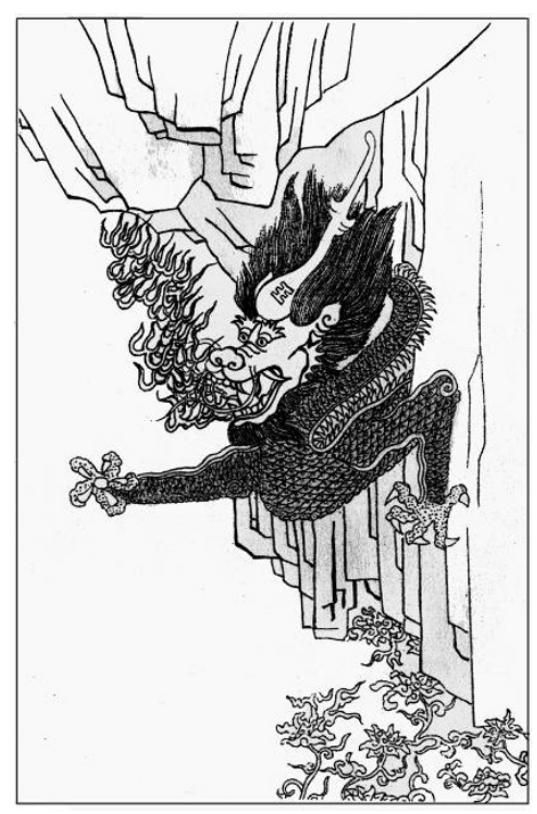

Figure 2 Zhu Long (namely the latent dragon), creator of the world, lying deeply beneath Zhong Mountain, is able to see clearly the Nether World with the torch held in his mouth. His sudden anger or seethe causes an earthquake (Drawn in the Qing Dynasty).

'Zhen' and 'dragon' are also used to signify the direction of east. In the ancient Chinese culture four holy creatures (black dragon, rose finch, white tiger and tortoise) are used to stand for the east, south, west and north, as well as spring, summer, autumn and winter, respectively. Coupled with the eight trigrams, it represents the elements of the universe and man, namely, '乾” (heaven), “坤' (earth), “艮' (mountain), “巽” (wind), “坎” (water), “离' (fire), “震' (thunder), and “兑' (pond). The combination of these elements can serve as philosophic stretch, for example, the four trigrams in the national flag of South Korea are 'heaven, earth, water and fire'. Figure 3 is an example, in which the concept of the east, spring or Vernal Equinox are equally expressed by three means: the seal character of '震', the figure of a black dragon and trigrams. Such symbols are commonly seen 
in amount of ancient Chinese bronze wares, divination plates, donate patterns or building marks.
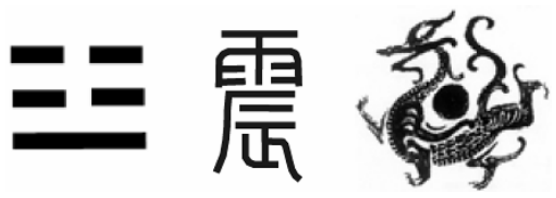

Figure 3 In ancient Chinese culture, the concept of the East and Spring (or Spring Equinox) is equally expressed by means of Eight Diagrams, seal character and figures.

There were different assumptions on the cause of earthquakes. One of Chinese thinker and philosopher Zhuangzi (some 369 BC-286 BC) said, "the sea water finishes a circle every three year, as waves approach, meet and collide with each other, an earthquake will occur". Such a world outlook of "the earth floating on water" was based on the discovery that when a well is being bug, water will spring up. As a result, an earth model in Chinese ancient times, which found its way by various paintings, patterns and sculptures, was only a three-layer structure of the sky, land and sea water. No further assumption was ever made on what is under the sea water, and the deepest place of the sea was called the Ninth Spring, as the Chinese word "ninth" means extreme profundity. Anyway, the above view that 'the colliding waves cause an earthquake' gained little ground in later generations, and it had limited social influence. Bo Yangfu (some the 8th century before Christ), a thinker in the late years of the Western Zhou Dynasty, made substantial contributions to the knowledge of earthquakes by putting forward the idea that 'the collision between Yin (negative) and Yang (positive) produces thunder, and their clash creates lighting' and 'quake generates thunder'. Here is his idea about the earthquake that happened in Shaanxi province in $780 \mathrm{BC}$ :

The vitality of the Heaven and Earth lies in their order; violation of the order causes commotion to the people. When Yang, submitted, cannot come out and Yin, suppressed, cannot evaporate, then an earthquake will occur. Now the three large rivers have been shaken, it is because that Yang has been displaced but Yin is suppressed. When Yang is lost and Yin still exists, the sources of the rivers are to be blocked, and the Kingdom is doomed.

It is certainly to have epoch-making significance and far-reaching influence to discard the physical con- tents such as deities, sea water and other substances, to abstract 'the vitality of the Heaven and Earth' into two elements: Yin (negative) and Yang (positive), and to understand earthquake from the conflicts of the two contradicting sides. Though the primitive philosophic view originated by him showed no concrete knowledge of geosciences and confused natural phenomena with social issues, yet, ironically, based on the premise that, "when the Yihe River and Luohe River dried up, the Xia Dynasty fell; when the Yellow River dried up, the Shang Dynasty ended", he made the prophecy that, "now that the Qi Mountain is collapsing and the Jinghe, Luohe and Weihe Rivers are running out of water, it is a sign that the Western Zhou is also going to fall", and the prophecy is turned out to be right. Later on, such an assumption was used as a basis to interpret the earthquake (519 BC) that happened in Luoyang during the Warring States Period as "When the Zhou Dynasty was falling, the three rivers were shaken. Now the subjects of the King of the Western Zhou are also shaken as they are to be given up by Heaven". It was said that it was the will of Heaven for the King of the Western Zhou to be knocked to death in the earthquake, and that he deserved it. The primitive divination concept had been trying to find an answer to the dramatic changes of the world from nature, and that pursuit continued till the Han Dynasty, and in the process, Bo Yangfu's notion of Yin (negative) and Yang (positive) developed into a metaphysics that still has its influence felt even today. So it can be considered a one-thousand-year-old idea.

\section{Second stage: Natural worship}

With knowledge of earthquake deepened, the fight came to a peak between ignorance and science and between conservatism and progressivism in the period of the Qin and Han dynasties (221 BC-220 AD). There appeared the seismic phenomenology of ancient China and Heng Zhang invented the first seismometer in human history during this period. However, the dominant seismic idea of the ruling class was still Yin-Yang and the Five Elements and the heavenly punishment. It was the first time in the history that an emperor issued a 'self-incrimination edict' due to an earthquake and that high officials were 'removed from office for an earthquake' during this period.

The contemporary Europe was in the flouring age of the ancient Greek and Roman civilization. It was also a primitive age of seismic knowledge, when Aristotle 
(384 BC-322 BC) believed that earthquake was caused by hidden solar heat in the earth, and when Lucretius (98 BC-55 BC) assumed that it was triggered by mountain landslides.

\subsection{Observation of seismic phenomena and the great invention}

After the unification of China by Qin Shi Huang in $221 \mathrm{BC}$, the development of farming boosted the astronomic observation and calendar timing to a higher level. Farming then was still frequently plagued by various natural disasters, many of them tangible and visible, such as drought, flood and locust disaster, but only earthquake is both incomprehensible and dangerous. People then paid attention to more of macroscopic phenomena, such as landslides, fires, surging water and collapse during earthquakes. Historical records had more information on the earthquakes and damage degrees in each prefecture and county. Starting from the Western Han Dynasty (206 BC), China began to have earthquake relief mechanisms, under which the government "built granaries to stock corns" in various names to carry out tax reduction and exemption, victim relief after earthquake. The official historian had a special duty to document earthquake as a particular disastrous abnormality into the official history. In the span of 440 years of the Qin and Han dynasties, over 120 earthquakes were documented. China's seismic phenomenology, a science of observation of microscopic phenomena of earthquake, was thus born.

Then the observational characteristics of frequent occurrence of earthquakes during the syzygy led to the connection of earthquake and astronomy, for instance, "the five stars traveled staggeringly, at night stars fell as rain, and earthquakes struck", "the sun was eclipsed, earthquake rocked Weiyang Palace", "earthquake occurs at the time of a solar eclipse", "when earthquake blasts, foreign stars are offending the moon", "when something is wrong with Vega, the heaven punishes in the form of an earthquake", "when solar eclipse happens on the first day of a lunar month, an earthquake ensues at night", etc. Despite of the materialistic observation at the royal observatory, the interpretation of natural phenomena was all of a royal mythological nature, still enshrouded in the concept of divination. Earthquake was regarded as an event by which the Heaven condemned the emperor and warned the common people, and consequently, the altar of heaven with a high platform was used for astronomic observation and heavenly sacrificial ceremony. The observatory was used to observe conflicts between Yin and
Yang and inauspicious omens. Later on, Chinese observational stations of astronomy, meteorology and earthquake were all simply called the 'observatory', though for most of the observatories there was no need to build a high platform. Therefore, the armillary sphere and seismoscope were invented and used mostly to, except that the former was also used to formulate calendars, serve the social requirements to make sure of the auspicious or inauspicious nature of astronomical phenomena, and heavenly and earthly disasters had to be revealed, prophesied and avoided by means of the observatory. This worship of nature interfered with no observation, but instead it urged our ancestors to diligently observe the heaven and earth, daring not committing any omission. Hence, here appeared the confusion of science and superstition, materialistic observation and religious worship, seeking after the natural laws and practicing divination (Feng et al, 2010).

Chong Wang (about 27 AD-97 AD), a great thinker in the Eastern Han put forward a philosophical view that "Earthquake is a natural movement of the Earth". The first outstanding scientist in China's science history was Heng Zhang (78 AD-139 AD), who invented the seismoscope, the first seismic instrument in human history, in August, $132 \mathrm{AD}$, with which the earthquake that happened in Longxi was successfully detected on December 13, 134 AD (Feng et al, 2006).

As for the invention of Heng Zhang's seismoscope, there existed physical foundation and social needs for the birth of scientific thought. People then had already clearly and commonly noticed that earthquake has mostly a feature of horizontal shaky motion. There are their special descriptions of earthquake in ancient text, such as "the earthquake shook the Capital; the earth quaked, setting the wine vessel swinging; the land swung and the mountain shook; people were shaken; houses and pavilions were swung", etc. The key word in these descriptions is 'shake or swing', suggesting that the physical foundation for their cognition is contingent on the shaking of hanging objects and the liquid surface. Using hanging objects as natural seismoscope had become part of daily life for common people by the Han Dynasty. For example, in both the government buildings and private residences, there were lots of pendent lamps, hanging paintings and calligraphies and a line of hanging writing brushes on the study desk, as well as stone chimes, bell sets, suspensions, sash weights, spinning hammers, buckets, hanging baskets, hanging meat, copper coins strung with and hanging from green silk cords 
or hemp cords, $\cdots$ and the list will never end. On top of all this, it was a fashion in the Han Dynasty to build high rises, buildings of three or four floors quite pervasive. Watchtowers, market towers, barn towers, look-out towers, block-house towers, bell towers, drum towers and tall gateways were quite the rage then, in addition to numerous high-platform building complexes sitting on highly-compressed earth platforms, similar to the Weiyang Palace, the Nine Temples, the altar of heaven, the Royal College, etc.

The structural magnifying effect of a high-rise building in an earthquake makes the oscillating and shaking of hanging objects more obvious and last longer. This was most likely to be noticed by the ordinary people and sent them panicking, to the extent that they would finally bear in mind the particular reaction of the hanging objects: they would not move without earthquake, and they would only move in an earthquake.
Therefore, the conceptual basis for the birth of Heng Zhang's seismoscope was supposed to be an imitation of the motion of hanging objects. The invention of Heng Zhang played an enlightening role in the birth of the modern seismograph in the 19th century (Milne, 1883; Herbert-Gustar and Nott, 1980). It is believed that perhaps the instrument got lost in the last years of the Eastern Han Dynasty, most likely somewhere after the notorious warlord in $190 \mathrm{AD}$, but not later than $221 \mathrm{AD}$. From in-depth research of relics in archeology and seismology, it is so far inferred that the interior of the seismoscope was composed of five parts: pillar, bolt, roadbeds, lever, and balls. Its triggering mechanism could detect weak seismic waves, and the seismic trigger phase was Rayleigh surface wave, and resonance played a role of magnification (Feng et al, 2006). Figure 4 shows the scientifically reconstructed model most recently finished.
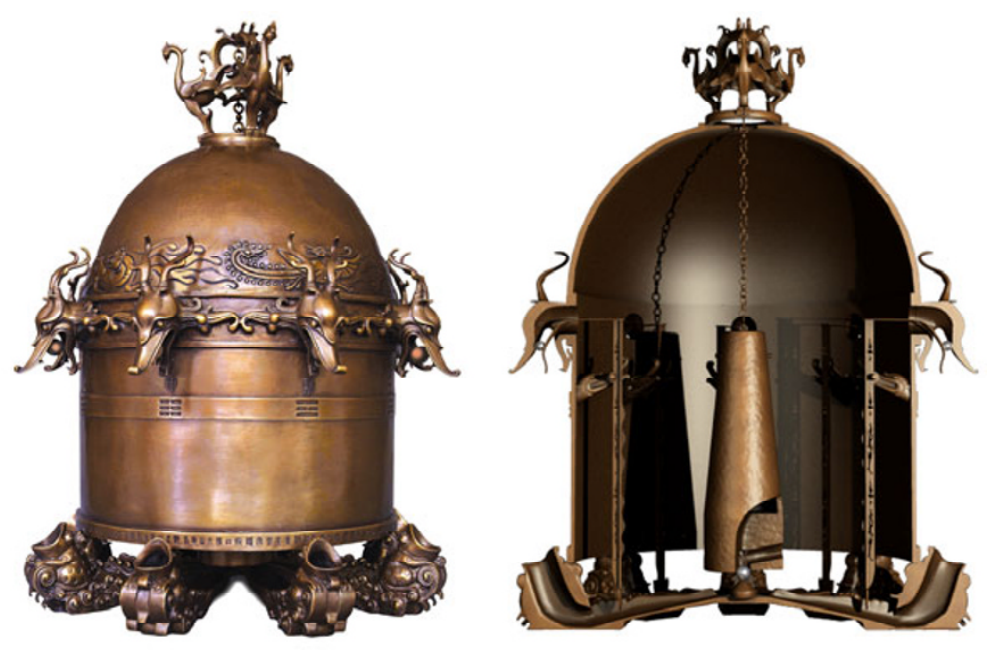

Figure 4 Interior of the newly reconstructed model of Heng Zhang's seismoscope composed of five parts: a general pillar, a bolt, eight roadbeds, levers and balls (Feng et al, 2010).

\subsection{Issue of 'self-incrimination edict' by the em-} peror and removal of officials due to an earthquake

In order to sustain the stability of the empire, in addition to the feudal hierarchy of 'monarch-official, father-son', a cultural notion of heavenly punishment was also needed. Like any other catastrophic abnormality, earthquake was deemed as a reprimand, condemnation, warning from the 'Heaven' to the king/emperor, so that officials could be given a chance to speak out about the law of the imperial court, to put forward expostulations for better administration, and to adjust conflicts.

It was Emperor Xuan of the Western Han Dynasty that issued the first imperial 'self-incrimination edict' in
Chinese history for an earthquake that struck Luoyang on June 1, 70 BC (Table 1). After the earthquake, Emperor Xuan, with reverence and awe, performed sacrificial rites to pacify the God of Earth, and held 10-odd stately ceremonies such as issuing a self-incrimination edict, soliciting suggestions from officials, appointing new officials, abolishing certain laws, abating taxes, paying homage to the royal ancestors at the courtyard, ascending onto the altar of Heaven, giving audiences to official historians, observing heavenly changes, adjusting the armillary sphere, declaring a truce and general pardon, wearing white plain clothes, keeping away from the main hall and dealing with no state affairs, changing 
Table 1 Cases in which the emperor issued a 'self-incrimination' and high officials were removed from office due to an earthquake in the Han Dynasty

\begin{tabular}{|c|c|c|c|c|}
\hline Case No. & Year of the earthquake & Emperor and reign title & Issue of self-incrimination edict & High official dismissed \\
\hline 1 & $70 \mathrm{BC}$ & Emperor Xuan of Han, Benshi & - & \\
\hline 2 & $67 \mathrm{BC}$ & Emperor Xuan of Han, Dijie & - & \\
\hline 3 & $48 \mathrm{BC}$ & Emperor Yuan of Han, Chuyuan & - & \\
\hline 4 & April, 47 BC & Emperor Yuan of Han, Chuyuan & - & \\
\hline 5 & Sept., $47 \mathrm{BC}$ & Emperor Yuan of Han, Chuyuan & - & \\
\hline 6 & $29 \mathrm{BC}$ & Emperor Cheng of Han, Jianshi & - & \\
\hline 7 & $13 \mathrm{BC}$ & Emperor Cheng of Han, Yongshi & - & \\
\hline 8 & $7 \mathrm{BC}$ & Emperor Cheng of Han, Suihe & - & \\
\hline 9 & $46 \mathrm{BC}$ & Emperor Guangwu of Han, Jianwu & - & \\
\hline 10 & $76 \mathrm{AD}$ & Emperor Zhang of Han, Jianchu & - & \\
\hline \multirow[t]{2}{*}{11} & 21 & Emperor An of Han, Yongning & $\bullet$ & \\
\hline & 132 & & \multicolumn{2}{|c|}{ Invention of Heng Zhang's seismoscope } \\
\hline 12 & 133 & Emperor Shun, Yangjia & - & $\bullet$ \\
\hline 13 & 134 & Emperor Shun, Yangjia & & $\bullet \bullet$ \\
\hline 14 & 136 & Emperor Shun, Yangjia & - & - \\
\hline 15 & 138 & Emperor Shun, Yonghe & & - \\
\hline 16 & 147 & Emperor Huan, Jianhe & - & \\
\hline 17 & 149 & Emperor Huan, Jianhe & - & \\
\hline 18 & 152 & Emperor Huan, Yuanjia & & - \\
\hline 19 & 154 & Emperor Huan, Yongxing & - & \\
\hline 20 & 161 & Emperor Huan, Yanxi & & - \\
\hline 21 & 165 & Emperor Huan, Yanxi & & - \\
\hline 22 & 171 & Emperor Ling, Jianning & & •• \\
\hline 23 & 173 & Emperor Ling, Xiping & & $\bullet$ \\
\hline 24 & 177 & Emperor Ling, Jiaping & & - \\
\hline 25 & 178 & Emperor Ling, Guanghe & & $\bullet$ \\
\hline 26 & 179 & Emperor Ling, Guanghe & & - \\
\hline 27 & 191 & Emperor Xian, Chuping & & $\bullet \bullet$ \\
\hline 28 & 193 & Emperor Xian, Chuping & & - \\
\hline 29 & Jane, 194 & Emperor Xian, Chuping & & - \\
\hline \multirow[t]{2}{*}{30} & July, 194 & Emperor Xian, Xingping & & $\bullet$ \\
\hline & 221 & & Han Dynasty fell & \\
\hline
\end{tabular}

the reign title, etc.

According to statistics, a total number of 619 reign titles have been used in Chinese history beginning from the 30th century Before Christ, the time of the legendary Yellow Emperor and Zhuan $\mathrm{Xu}$, up to now. The occurrence of the earthquake in the capital (Luoyang) led to the change of reign title from 'Benshi' to 'Dijie', praying that 'the earthquake will be more moderate'. Such a cranky reign title ran counter to the usual practice of adopting a reign title beginning with an auspicious character such as heaven, treasure, everlasting, light and so on. This would have been the only example in Chinese history to have a reign title. For 21 times in Chinese history emperors issued such 'self-incrimination edict' for earthquake, mostly during the Han Dynasty (16 times), the last time being during the reign of the Tang Dynasty (778 AD). The corresponding ceremonies involved came in different levels of complexity, and most of the edicts read to the effect that "as the emperor, I am too unworthy to be in good service to the Heaven and Earth. I have incurred this condemnation from God for failure to be wiser in attending to state affairs" and other such empty words. Beginning from 154 AD the Emperor Huan in the late years of the Han Dynasty stopped making self-criticism for earthquake; hence abandonment of the practice of offering sacrifices to Heaven and Earth (Table 1).

It was a tradition in the Qin and Han dynasties to punish high-ranking officials on the pretext of flood, drought, locust hazard, plague, solar/lunar eclipse, but, in fact, none of the high officials was ever prosecuted due to any earthquake. The invention of the seismoscope by Heng Zhang in $132 \mathrm{AD}$, however, changed the rule dramatically: in 133 and 134, two batches of high officials of overwhelming powers, all of the top three ranks (Situ, Taiwei and Sikong), were successively "removed from office because of earthquakes", incurring grave social impacts. Such practice was the first in Chinese history where high officials were prosecuted on account of an earthquake, and there were 16 such cases in total in the Han Dynasty. It was obviously ridiculous that people then were still unable to get a scientific understanding of 
earthquake, getting the natural phenomena confused with some social issues, thus the tragedy for Heng Zhang and his seismoscope. The frequent occurrence of earthquakes would instantly be transformed to power struggles in the officialdom where "officials were disciplined on the pretext of the earthquake" and the increasingly intense conflict continued till the downfall of the East Han Dynasty. It was not until the period of the Three Kingdoms (220 AD-280 AD), the Northern Wei Dynasty (220 AD-265 AD), and the Jin Dynasty (265 AD-420 AD) that such bad practice was abandoned.

\section{Third stage: Perceptual knowledge}

It was from $220 \mathrm{AD}$ of the Three Kingdoms Period to 1722 of the reign period of Emperor Kangxi, spanning 1500 years that the basis of China's historical data on earthquake was laid.

As part of the sustained development of Chinese culture over the past thousands of years, China had a comfortable lead in science and technology during the Song and Yuan dynasties (10th-14th century), unmatched by any other nations. However, China's scientific system then belonged to the category of phenomenology, guided by practicability, and directed to provide solutions to particular problems. In the early stage of scientific development, such train of thought was a reasonable approach not only necessary but effective; but this pragmatic science was near-sighted, satisfied with knowing the phenomena rather than what was behind them, and therefore once there was no direct request from reality it would lose drive. The attitude swayed the seismic study in this period was featured by a "bias in favor of observing phenomena against technical improvement and theoretical exploration".

\subsection{Confused knowledge and end of the view of heavenly condemnation}

Dufang Xing in the Northern Qi Dynasty, Xiaogong Lin in the Sui Dynasty, Shaoyu Jiang in the Song Dynasty, and Mi Zhou in the Yuan Dynasty (around 1290) all wrote something about the seismoscope by Heng Zhang and issues of seismic observation, but they all held a sceptical attitude.

When an earthquake struck Shanxi in 656, Emperor of the Tang Dynasty issued an edict, stating "I confused the relation between politics and religion", to claim responsibility for the earthquake. But the Buddhist monks thought differently, deeming the earthquake of Luoyang in 699 as a good phenomenon as it resulted from
Sakyamuni showing his presence. Here scholars were baffled, and no wiser was the Emperor. It was not until after the earthquake of Chang'an in 788 when Emperor Dezong of the Tang Dynasty issued an edict of perfunctory self-incrimination that the long history of imperial 'self-incrimination edict' came to an end.

The Song Dynasty was a period of exceptionally violent earthquake. After the earthquake in 999, though some official once reported to the emperor that "I have read about solar eclipses and earthquakes and the consequent imperial edicts in the Book of Han", so he begged the emperor 'to condescend to conduct ceremonies and issue generous edicts' to relieve earthquakes, yet such appeal met with no response. Earthquake killed 32000 people in Dingxiang, Shanxi in 1038, 25000 in Beijing in 1057 and over 10000 in Guyuan, Ningxia in 1219 (Li, 1981; Gu, 1983). High officials in the Song and Yuan dynasties had to resort to time-honored Yin (negative) and Yang (positive) trigrams and Taoist sacrificial rites to appease the people. Only after the 1279 and 1322 earthquakes which caused serious damages did the officials responsible plead guilty and ask for dismissal. The emperors wound up all these by simply saying 'No' to these dismissal applicants.

In the last years of the Qing Dynasty, the response from the emperor became increasingly simplified. His response to an earthquake report usually took three words only: "I got it", and no more. Numerous documents carrying such imperial comments are preserved. Obviously, it was impossible to rely on this China's traditional scientific system, long centered on agriculture and based on practicability, to cope with such complicated inner motion of the earth.

\subsection{Two extreme practices and one remedial measure}

The 1303 earthquake in the Yuan Dynasty caused exceptionally grave damages to Hongtong and Zhaocheng, Shanxi province, and the aftershocks continued for 3-4 years; then the 1556 earthquake in the Ming Dynasty striking Huaxian county, Shaanxi province, claimed 830000 lives, the worst one in history $(\mathrm{Gu}, 1983)$. Once driven to an impasse by nature, researchers of the phenomenology would invariably go to two extremes: either only to document any earthquake, or to boldly make earthquake prophecies. The one remedial measure here refers to the governmental after-earth- quake relief.

As for seismological documentation, the printing technique of movable type invented in 1041-1048 during Northern Song Dynasty boosted the tremendous development of local chronicles of each region of China in 
the Song, Liao, Jin and Yuan dynasties, with 1031 local histories in this period of 409 years alone, compared with these numbering less than 400 in a period of 1100 years in the Han and Tang dynasties, a perceptible amount increase of seismological documentation (Du, 2003). These historical documents not only described the position of the sun, moon, and stars, damages to houses and structures, quake-proof characteristics but countless abnormal phenomena of the earthquake sound, ground water, animals, weather, organisms, static electricity, gas overflow, etc. The continued effort of our ancestors over the past thousands of years has left us large quantities of written documentation of earthquake peerless in the world, a data basis for us now to draw seismic intensity zones, carry out macro studies and statistical analysis, and a fundamental database for earthquake security assessment, contributing to the particular scientific study of earthquake.

Undoubtedly, technological content in such historical documentation is on the weak side. Written by officials and used for earthquake relief, these records documented earthquakes 'more defined in general terms than specific quantity; more described than analyzed', making it hardly likely to apply them in modern scientific work. In terms of the documentation frequency of these historical data on earthquakes of magnitude 4.7 or above in the past 3000 years, the frequency was below two times per 10 years for most of the time before the Song Dynasty (960 AD); when printing technique was invented in the Song Dynasty, the frequency increased to three times per 10 years; after the invention of seismograph in 1900, it reached 100-1000 times per 10 years. This shows that the effective time interval of earthquake events is only about 1000 years, and the maximum cycle of seismic activity that we are allowed to infer does not exceed 500 years.

Making prophecies about earthquake by means of horoscope and divination is a legacy from the pre-historical ages. Perhaps it is an order of nature first discovered by Chinese that earthquake strikes most frequently and violently on syzygy. Let's cite some events for illustration. In $29 \mathrm{BC}$ of the Han Dynasty, "On syzygy, solar eclipse occurred in the daytime, and then an earthquake struck at night" (The Book of Han); in 120 of the Eastern Han Dynasty, "On syzygy solar eclipse occurred in the daytime; soon afterwards, earthquake hit eight regions"; in 1068 of the Song Dynasty, "Earthquake struck again, and at night lunar eclipse occurred" (The History of the Song Dynasty), etc. Each of the Chinese dynasties over the tens of thousands of years abounded in historical documentation of such characteristic, which has become a stable feature of China's seismic activity. Yet there is still no knowing how our ancestors made earthquake prophecies mystically. Fortunately, there remains some precious record left behind by an Italian named Marco Polo (1254-1324), who came to China in 1275 and stayed here for 17 years, and it was just the beginning of the Yuan Dynasty. His travel notes in 1295, which has unveiled the then official mysterious events, is the only relevant information discovered by us so far.

\begin{abstract}
"They had their own astrolabe marked with the symbol, time and each of the positions of a star around the year. Each school of astrologists will review their diagrams to determine the orbits of spheres and their relative positions. Here, on the constellation orbit of each symbol detect changes to astronomical phenomena, and then make prophecies of monthly abnormal phenomena. For example, they will forecast thunder, rainstorm, earthquake in a month; lightning and torrential rain in another month; sickness, death, war, conflict, conspiracy in yet another month, etc. Once they find omens to an event on their astrolabes, they will make predictions; still, they will state at the same time that Heaven may change their judgments at his discretion more or less."
\end{abstract}

In a positive sense, this ancient Chinese deductive train of thought by exploring the relation between the sun, moon and earth 'was nothing short of the forerunner of research on earthquake prediction by Chinese people' (Li, 1981). Of course, there is much more to astrology that satisfies certain social needs and such influence lives on.

The remedial measure after an earthquake was relief. China's earthquake relief began in the Western Han Dynasty, and by the Ming and Qing dynasties, a whole set of relief system, with rigorous provisions on the report on earthquake and other natural disaster and procedures for earthquake investigation and relief, had been developed.

\subsection{Earthquake during thign of Emperor Kangxi}

This has been a major event in the history of Chinese seismology. By the early days of the Qing Dynasty, especially by the reign of Emperor Shunzhi and Emperor Kangxi (1644-1722), Europe had gone through 
the Renaissance and out of its cultural low ebb. At the request of Emperor Kangxi, France once sent six advanced scholars who stayed for a long time in Chinese royal palace. Great numbers of missionaries, coming from France, Italy, Belgium and other European countries to China, brought Western knowledge of astronomy, mathematics, physics and mechanics, which had a vital effect on the scientific activity of Emperor Kangxi. It was a period of frequent strong earthquakes, especially major ones of magnitude 8 or above, for instance the earthquake of Tianshui in 1654, of Tancheng in 1668, and of Pinggu, Sanhe, in 1679, all causing tens of thousands of casualties. The last one left profound and far-reaching social impacts. It is now called 'Kangxi earthquake'.

The earthquake happened on September 2. Its particularity lies in that: First, it was an earthquake with magnitude 8 that had struck within the capital district in Chinese history, which proceeded by obvious foreshocks, killed 50000 people and damaged the Imperial Palace; Second, Emperor Kangxi adopted an exceptional series of drastic measures. Within four hours after the earthquake, he gathered his high officials to find out solutions, and he moved into a tent; on the second day, he issued an edict to distribute relief to earthquake victims; on the third day, he announced what he considered the administrative malpractice; on the fifth day, he ordered that the salaries of officials to be cut by half; on the tenth, he came up with an initial draft of law to carry out relief and corruption purge simultaneously; on the fifteenth at the Middle Autumn Festival, after spraying at the Temple of Heaven, the emperor immediately resumed discussion on the earthquake. Such measures had never been heard of before.

Last, Emperor Kangxi, a lover of mathematics, began to shift his interest to earthquake, and formed this set of views on earthquake. He was the emperor who first resolutely disproved the absurdity of 'dismissal of high officials for earthquake' and wrote a science essay of new thought 'Earthquake', in which many views contained should tally with those of modern seismology (Figure 5).

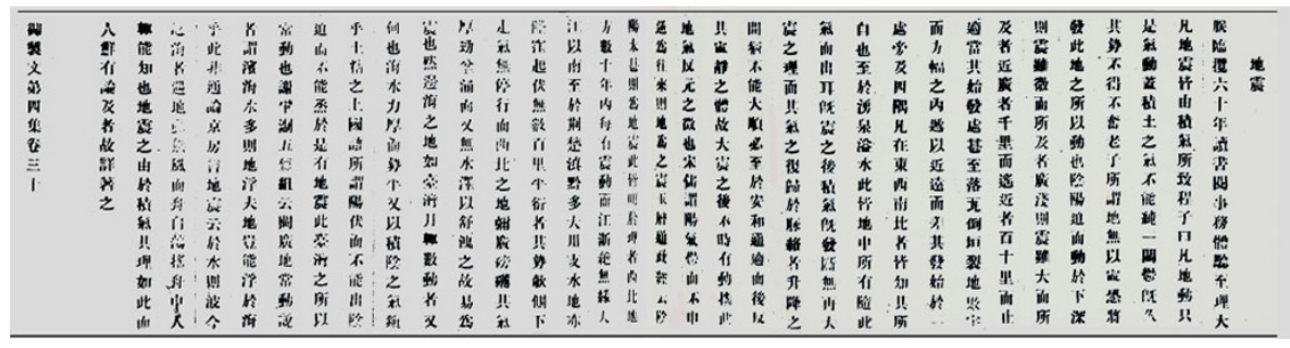

Figure 5 An article written by Emperor Kangxi (collected in Yuzhiwen, the 10th year of Yongzheng). This essay, which sealed the end of an old age, is one of the highest levels on earthquake we have read over the 1000 -odd years since Heng Zhang.

\section{Fourth stage: Scientific exploration}

The years from the reign of Emperor Kangxi to now, with 1911 as the demarcation year, are divided into two periods: modern history and contemporary history. China made brilliant contributions to the discovery of abnormal pre-earthquake phenomena and exploration of earthquake prediction, and achieved a great leap forward in seismic phenomenology. Meanwhile, by 1830, Europe had gone through the industrial revolution. Modern seismology began around 1900, and is still a newly born rising science.

\subsection{Modern period: Discovery of abnormal pre-earthquake phenomena}

China boasts the world's richest record of abnormal pre-earthquake phenomena. The earliest was the record on the seismic sound before an earthquake of Yanmen Prefecture, Shanxi, in 474 of the Northern Wei Dynasty: "Thunder-like sound rumbled on the rough city-wall of Yanmen, then 10-odd peals arose from the far west; when the sounds stopped, an earthquake began to strike". Abnormal animal behaviors were also discovered before an earthquake in 650 of the Tang Dynasty: "Mice gathered at the imperial court and squeaked in the markets and roads; cracks appeared on the ground and rooms", etc. Globally, qualities of discovery and documentation of abnormal pre-earthquake phenomena occurred first in the 15th-17th century during the late Ming and early Qing period in China, and about the 18th-19th century in Japan. The documentation of other countries was much later and less (Milne, 1890). According to the statement of the US Geological 
Survey, the Greek people were believed to have been the first to have discovered the abnormal behaviors of animals before an earthquake, and they recorded that mice, weasels, snakes and centipedes had fled their nests several days before an earthquake in $373 \mathrm{BC}$. Listed in Table 2 are some of the earliest seismic cases in historical documentation.

Table 2 Earliest historical documentation of anomalies before earthquake

\begin{tabular}{|c|c|c|c|}
\hline Category & China's historical document & $\begin{array}{l}\text { Seismic cases } \\
\text { in China }\end{array}$ & Foreign cases \\
\hline \multirow[t]{2}{*}{ Seismic sound } & $\begin{array}{l}\text { Thunder-like sound rumbled on the rough city-wall of Yanmen, then } 10 \text {-odd peals arose from } \\
\text { the far west; when the sounds stopped, an earthquake began to strike. }\end{array}$ & 474, Shanxi & \\
\hline & $\begin{array}{l}\text { The people of Qinzhou had heard rumbles coming from underground in the northwest, and soon } \\
\text { after, an earthquake struck. }\end{array}$ & 734, Gansu & \\
\hline \multirow[t]{2}{*}{ Fore-shock } & $\begin{array}{l}\text { In May, the earth quaked for } 13 \text { consecutive days in Yunnan; in August a severe earthquake hit } \\
\text { Yunnan. }\end{array}$ & 1512, Yunnan & \\
\hline & The earthquake struck, before this it had stricken once several days, but it struck severely today. & 1668, Tancheng & \\
\hline \multirow{2}{*}{$\begin{array}{l}\text { Underground } \\
\text { water }\end{array}$} & The day before the earthquake, I heard the roaring sounds of the river. & 1668, Tancheng & \\
\hline & $\begin{array}{l}\text { Two years before the earthquake, water suddenly began to trickle from the Runde Spring of } \\
\text { Qishan County which had dried up for many years. }\end{array}$ & 1739, Henan & 1751, Japan \\
\hline \multirow[t]{2}{*}{$\begin{array}{l}\text { Earthquake } \\
\text { light }\end{array}$} & $\begin{array}{l}\text { Bluish green light flashed six to seven times like lightening bolts, and there indistinctive sounds } \\
\text { like drumbeats; soon, an earthquake struck. }\end{array}$ & 1509, Hubei & 1703, Japan \\
\hline & Rumble and light appeared in the sky, and after a while an earthquake struck. & 1637, Yuanjiang & 1847, Japan \\
\hline \multirow[t]{2}{*}{ Meteorology } & A rainstorm struck suddenly, and the earth quaked violently. & 1523, Dinghai & \\
\hline & Gusts, showers and hail preceded came first, which was followed by an earthquake. & 1902, Artux & \\
\hline \multirow[t]{2}{*}{ Gust } & $\begin{array}{l}\text { A dark wind struck suddenly, and there came a sound like thunder; soon afterwards, the earth } \\
\text { shook violently. }\end{array}$ & 1219, Shaanxi & \\
\hline & There suddenly appeared a strong wind, followed soon by an earthquake. & 1303, Hongtong & \\
\hline \multirow[t]{2}{*}{ Ground vapour } & $\begin{array}{l}\text { Suddenly, clouds and mists rose from the foot of the mountain, and a sound was becoming } \\
\text { louder and louder, and then the earth shook. }\end{array}$ & 1072, Huaxian & 1802, Japan \\
\hline & The sky was shrouded in clouds and suddenly the earthquake struck like thunder. & 1655, Weinan & 1855, Japan \\
\hline \multirow[t]{2}{*}{ Terrestrial heat } & $\begin{array}{l}\text { Some knowledgeable old folk said when great heat appeared after an excessive rain it was ad- } \\
\text { visable to be on guard against an earthquake. }\end{array}$ & 1815, Pinglu & \\
\hline & The day before the earthquake a torrential rain poured down and it was extremely hot. & 1917, Daguan & \\
\hline \multirow[t]{3}{*}{ Animals } & $\begin{array}{l}\text { Mice gathered at the Imperial Court, squeaked on the markets and street; fields and rooms } \\
\text { showed cracks. }\end{array}$ & 650, Shaanxi & $\begin{array}{l}373 \text { BC, Greece } \\
1783 \text {, Italy }\end{array}$ \\
\hline & Before the earthquake, birds in their nests scattered in panic. & 787, Shaanxi & 1812, Venezuela \\
\hline & & & 1855, Japan \\
\hline
\end{tabular}

The discovery of abnormal pre-earthquake phenomena, a great leap in perceptual knowledge. So far, China had further accumulated the world's richest data on pre-earthquake abnormal phenomena, extracted numerous important precursors usable for earthquake prediction. Regrettably, people of that age were not aware of its value, nor did they generalize or popularize their experience.

In the last years of the Qing Dynasty, the scientific train of thought represented by Heng Zhang's seismoscope was promoted overseas, and modern seismology came into being. In 1703, Frenchman J de la Haute Feuille invented the first seismic instrument of Europe: the mercury seismoscope (Dewey and Byerly, 1969). In 1829, Poisson laid the theoretical foundation of seismic wave. In 1875, for the first time, Hattori (first president of Seismological Society of Japan in 1880) restored the exterior shape of Heng Zhang's seismoscope. In 1883, Englishman Milne J (1850-1913) again studied and reconstructed the instrument (Milne, 1883), and then during 1892-1894, the first horizontal seismograph in the world that could be universally installed at any station was created and a global seismic network was established, thus the founding of modern seismology. It was Milne who was the first to have translated the 196 Chinese characters recorded in the Book of the Later Han describing Heng Zhang's seismoscope into English and introduced it to the world, stating to the West that "The earliest seismoscope of which we find any historical record is one which owes its origin to a Chinese called Heng Zhang" (Herbert-Gustar and Nott, 1980).

While the Qing Dynasty was defeated in the War of 1894, the Frenchman Gauthier began to carry out his geomagnetism observation in a Catholic Church of 
Shanghai. In 1897, Japan first installed the seismograph newly invented by Milne in Taiwan. In 1904, Japan installed the Omori Seismograph in Dalian and Shanghai. Germany established a seismic station in Qingdao in 1909. Wenhao Wong (1889-1971), who had studied in Belgium, became China's first Ph.D. in geology and the first seismological scholar and returned to China to conduct scientific research in 1912. In a China that was semi-colonial and semi-feudal, which bore war-torn signs everywhere and where the people found it hard to live on, China's seismology started its arduous journey.

\subsection{Contemporary period Establishment and de-} velopment of the scientific seismology

In this period, China's modern seismological research made great headway. Divided by the earthquake of Xingtai in 1966 and that of Wenchuan in 2008, this period can be further divided into three phases with different historic missions for three generations of seismologists to undertake.

1) Foundation-laying phase. After the 1911 Revolution of China, the Industrial Ministry of Nanjing Central Government established a geological department under the Mining Division in 1912, changed in 1913 as a Geological Survey (headed by Wenjiang Ding), and on December 21 of the same year, president of the College of Industry Hongyi Zhang finished his first investigation on Yunnan earthquake of magnitude 7. The first isoseismic-lines were drawn by Jichen Liu for Anhui earthquake in 1917. In 1930, Shanbang Li set up the Beijing Observatory, and in 1931, Yongshen Jin established the Nanjing Seismic Station. In 1931, Yingwei Wang finished China's first seismic monograph Modern Seismology. In 1942, Shanbang Li designed and made China's first modern seismograph (Figure 6). In 1944, Chengyi $\mathrm{Fu}$ in USA became China's first Ph.D. in geophysics. In 1947, the Chinese Geophysical Society was established (with Zongqi Chen as president). However, there were only three seismological professionals before the liberation of China in 1949.

After the founding of the People's Republic of China in 1949, the seismic undertaking was carried out in four main aspects: bringing the seismic study into the national plan, establishing research institutions to train professionals, serving project construction centered on the compilation of seismic zoning maps, and establishing the national seismic observation system. For instance, in 1953, the Earthquake Working Committee, Chinese Academy of Sciences (CAS) was set up. And later, the research task of prevention of seismic disasters and earthquake prediction was included into the $\mathrm{Na}$ tional Perspective Plan for the Development of Science and Technology (1956-1967). The Institute of Geophysics, CAS was established in 1950, headed by Jiuzhang Zhao. A batch of Western returned scholars began to train seismological professionals for the newly established People's Republic of China. Nation-wide networks of seismic and magnetic observatories were developed, and the seismic division was carried out in a large scale. The hard effort by China's first generation of seismologists laid a foundation for scientific research, and each piece of their work, all foundation-laying in nature, was to be remembered by later generations.

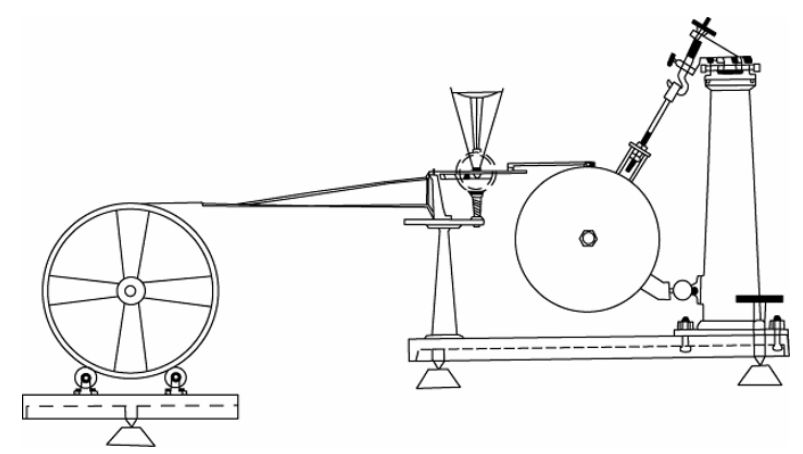

Figure 6 The first seismograph designed by Chinese scientist Shanbang Li (made in 1939-1942).

2) Prediction exploration. After the Xingtai earthquake in 1966 (death of 7000 people), under the leadership of Premier of Enlai Zhou, China's earthquake prediction entered a phase of exploration. The guideline for the seismological work was to give priority to prevention, to combine effort of professionals and the general public, to explore diverse ways, to strengthen research into seismic prediction and engineering seismology, and to promote the modernization of seismological science and technology. After 1971, the national earthquake administration and provincial bureaus were set up successively. In 1979, the Seismological Society of China was established with president of Gongxu Gu. In 1998, the Law of People's Republic of China on the Earthquake Prevention and Relief came into effect. In 2000, the State Council called for the establishment and perfection of the three main working systems, that is, seismic monitoring and prediction, seismic protection and emergency rescue, which has proved to be successful in numerous trial forecasts.

The main force of China's seismological research in this phase were professionals of every categories trained 
during or before the Cultural Revolution (1966-1976). As China's second generation of seismologists, they made history by establishing China's scientific research system for seismic monitoring and prediction; they were pioneers in their areas, some have died in earthquakes, and finally their effort has made China's seismology reach the world's advanced level. By then, the workers of the seismological institutions and units numbered some 20000 . The forecast of Haicheng earthquake of 1975 succeeded; the disaster of the Tangshan earthquake in 1976 (death of 242000 ), reflected the underdeveloped characteristics of the earthquake prediction then.

3) New phase of exploration and research. Whatever the perspective, Wenchuan earthquake of magnitude 8.0 in 2008 will come down in history as a historical mark. Whatever the appraisal of its tremendous shock and profound impact on China's seismological research, it will be no exaggeration. The academic world begins to calm down for reflection and make drastic adjustment, and finally people have returned to the departure point of dispute: "whether earthquake is predictable?" A new historical age is likely just around the corner. The implementation of the Outline of the Development of National Science and Technology in Seismology (2007-2020) will make for the arrival of this new era. This new generation who have grown up after the Cultural Revolution, China's third generation of seismologists are expected to observe the 100th anniversary of the Xingtai earthquake by making some breakthrough in earthquake prediction.

\section{Learning from history and blazing a trail for the future}

Globally, earthquake prediction is still in its stage of development, falling far short of social needs. This paper is just a review of the issue of scientific and technological innovation in terms of history and culture of Chinese seismology.

\subsection{Historical hurdles to progress}

1) Subconscious submission to authority and conformity. Maybe it is the primary mental scruple and maladjustment that inhibits and jeopardizes our innovation in science and technology. For the absence of the development stage of capitalism in China, the feudal cultural and the mentality of centralization of power over the past thousands of years have left deep imprints on us. On the contrary, the development of science is impossible without scientific criticism, and the vigor of thoughts and enormous drive brought about by academic contention are usually luxuries we are not entitled to enjoy without first advocating. Over the ages, China's traditional culture has been featured with little mythology and originality. In a word, all this has produced a traditional Chinese culture that is far from imaginative, inactive in thought, which has directly undermined the inspiration and soil for innovation in science and art.

2) Habitual phenomenological research. China's earthquake prediction, with a phenomenological thinking foundation, has been carrying on the practicable tradition that originated during the Qin and Han dynasties, being used to making 'phenomenon to phenomenon' analyses and good at inference as simple as 'learning to read by assistance of pictures', so much so that once some generalization or extrapolation based on observation of phenomena, opinions of forecast will be formed, giving no consideration whether modern science supports such phenomenological relation. Despite of the tremendous enhancement and change of observation technology over the past 30 years, the phenomenological research practice has remained the same, no progress in the conventional mentality, making it hard to generalize the successful and unsuccessful experiences of earthquake prediction in China.

It is noted that the Western science and technology is advancing along another road, with a goal of pursuing the order of nature and theoretical frame, making deductive inferences based on experimental causation, a practice that shows slow progress in the initial stage but great vigor later on. The consequent series of modern theories and innovative technologies, including the plate tectonics, seismic source mechanism, satellite observation, etc, though not response to the immediate appeal for earthquake prediction, have played a guiding role in earthquake prediction.

3) Methods of philosophical analysis without sincerity. China is no cradle of modern mathematics, physics and chemistry and as such lacks the richness of Western culture these aspects and has have no foundation-laying contribution thereto. It sounds that there is always some charm and lingering appeal missing from a symphony played with imported instruments. Of all the countries of the world, China most urgently calls for the realization of earthquake prediction as soon as possible. Yet, though the government has invested a lot on physical equipment, we lack long-term investment and stringent training in fundamental experiments and fundamental theories. The thinking of our researchers will 
prove to be on the weak side in terms of quantitative analysis and formal logic. When shifting from perceptual knowledge to rational knowledge or from phenomena to nature, they tend to find it beyond them, and subconsciously replace professional analysis with empty philosophical talk.

We are inclined to generalize simply issues of different natures as the formula of two elements: "when stress gets concentrated, it will be adjusted; when energy gets accumulated, it will be released", nothing short of the 'Yin and Yang dialectics' of the late years of the Western Zhou Dynasty. In contrast, Western scholars tend to approach a problem in terms of theoretical mode, experimental condition, parameter variation, causation, and etc, and it follows that their analysis of nature shows more quantification and rationality.

\subsection{Adoption of a policy more in line with the cur- rent prediction level}

Prediction, which represents the highest level of human capacity in mastering the order of nature, usually goes through three stages of development: phenomenological empirical prediction, quantitative statistical prediction, essential physical prediction. In contrast, the current earthquake prediction is still in its infant stage, the disaster relief policy immature. We should act as permitted by this historical stage, the practical way adopted in earthquake prediction still merits recognition, for as part of an oriental scientific system; it is in line with the characteristics of the immature science and serves to alleviate disaster to a degree. Obviously, from the perspective of the long-term growth of seismological science, there is little room for the development of this practicable practice, for, to the final analysis, the empirical thinking is still confined at the preliminary stage of knowledge, and real innovation is possible only through experimental and theoretical effort.

As for the disaster mitigation policy, the inadequacy of professional prediction necessitates that all the community should be allowed to participate in seismic precaution. As the saying goes, "it is a bad idea to put all the eggs in one basket". Maybe it is more in line with the current seismological level to adopt the qualitative and time-varying seismic early-warning system instead of the quantitative and conclusive forecast. Once the early warnings of various degrees are issued, the general public get the message that "there is some danger ahead but it is not sure", and such right to know allows them to take active precautions.

\subsection{Promoting multicultural coexistence and inte- gration}

It is neither possible nor necessary to eliminate the difference between traditional Chinese and Western cultures. The development of science and technology in the 21st century has shown global cultural innovation, which is more remote from daily life and featured with some "homo-taxis", so much so that it is hard for any nation to maintain its lead in scientific and technological achievements in an isolated state for over half a century. When it comes to earthquake prediction, any single culture, however historically rich it may be, will betray its limitation and weakness. Therefore, multicultural coexistence and integration will become a global necessity. It goes without saying that, on thorny issues, such as the research on geodynamics, earthquake prediction, and tsunami early warning, and on notions of understanding seismic mechanism, seismic fortification, and emergency search and rescue, China's seismology has to take bigger strides to get into the world, and it is sure to benefit from the communication, clash and fusion of cultures.

In short, cultural problems are to be solved culturally, a task beyond any individual. This is another noteworthy train of thought.

\section{Conclusions}

1) To fight earthquake, man has been improving relations between man and nature, as well as interpersonal relations. Chinese culture, formed over the past thousands of years, proves to be a double-edged sword for us; historical imprints of feudalism has been affecting incisively our work today; it is time to get a rational idea of "where I have come from, and where I am going to", so that we can learn from history and blaze a trail for the future.

2) The history of Chinese seismology can be divided into four stages, that is, the stage of primitive knowledge in the Pre-Qin period, of nature worship in the Qin and Han dynasties, of perceptual knowledge in the ensuing period, and of scientific exploration from the reign of Emperor Kangxi up to now. China's seismic research is rooted in phenomenological thought and dominates by practicability. The bias "in favor of phenomenon observation and against improving technology and deepening rational knowledge" since ancient times has led to a weak foundation for modern science.

3) China's four major contributions to the development of the world seismology are: (1) the seismoscope 
invented by Heng Zhang in 132, the first seismometer in human history; (2) historical seismic documentation (1831 BC-now), the only wealth of recording that spans 4000 years; (3) documentation of abnormalities before earthquake (474 AD-now), the richest and earliest discoveries; (4) prediction of earthquakes including Haicheng earthquake (since 1975), the earliest successful practice in the world.

4) Despite of the great headway of China's modern seismological study, it is still at its toddling stage, and our policy of seismic mitigation is far from fully-fledged. We are still weighed down by historical baggage, such as subconscious submission to superiors and conformity, phenomenological research practice, and the practice of substituting empty philosophical talk for scientific analysis. From now on, it is advisable for us to make further effort to combine phenomenological research with experiment, observation, and theoretical research, to adopt policies more in line with the current level of seismic prediction, to advocate multiculturalism, in an effort to a high-level Chinese culture of seismic research.

Acknowledgements The authors would like to be grateful to Xuan $\mathrm{Wu}$ for computing the historical earthquakes, also to professors Zengjian Guo, Guomin Zhang, Zhonghuai Xu, Zhenliang Shi, Yun-tai Chen and anonymous readers for their careful reading and suggestions. The contribution No. is 10FE3003, Insititute of Geophysics, China Earthquake Administration.

\section{References}

Dewey J and Byerly P (1969). The early history of seismometry (to 1900). Bull Seism Soc Amer 59(1): 183-227.

Du S R (2003). History of Chinese Science and Technology. Science Press, Beijing, 908-911, 921-970 (in Chinese).

Feng R, Li X D, Tian K and Wu Y X (2010). Innovation, lost and historical succession of Zhang Heng's Seismoscope. Zhongyuan Wenwu 1: 88-98 (in Chinese).

Feng R, Tian K, Zhu T, Wu Y X, Zhu X M, Li X D and Sun X L (2006). Scientific reconstruction of Zhang Heng's seismoscope. Study in the History of Natural Sciences 25(Suppl.): 53-76 (in Chinese).

Feng S (2001). Archaeoastronomy in China. China Social Science Documentation Publishing House, Beijing, 12-51, 302-320 (in Chinese).

Gu G X (1983). Seismic Catalogue of China. Science Press, Beijing, 1-894 (in Chinese).

Herbert-Gustar L K and Nott P A (1980). John Milne: Father of Modern Seismology. Paul Norbury Publications Ltd, Tenterden, Kent, 1-188.

Li S B (1981). Earthquake in China. Seismological Press, Beijing, 167-244 (in Chinese).

Milne J (1883). Earthquakes and Other Earth Movements. Kegan Paul Trench, Trubner and Co. Ltd, London, 1-235.

Milne J (1890). Earthquakes in connection with electric and magnetic phenomena. Trans Seism Soc Japan 15: 135-162. 